\title{
Parkinson pioneers blaze trail of controversy
}

On a steamy day in August, doctors at Weill Cornell Medical College in New York City injected virus particles, laden with a gene to dampen overwrought neurons, deep into Nathan Klein's brain. The aim: to rid him of Parkinson disease.

The trial may seem bold, but it is only the latest in a series of seemingly drastic schemes cooked up to treat the disorder. Implanted electrodes that zap brain cells, a drip feed of nutrients to keep the cells alive, even transplants of aborted fetal tissue have all found their way into human guinea pigs with Parkinson disease.

One obvious reason therapies for the disease are so aggressively pursued, say experts, is the fierce demand from patients: an estimated 4 million people worldwide suffer from the disease. The standard treatment, the drug levodopa, proves insufficient over time and causes severe side effects. The call for effective treatments has also been fuelled by the advocacy of celebrity patient Michael J. Fox.

That aside, the disorder is a good practice ground for therapies because its underlying brain chemistry is well defined. A group of neurons that make the neurotransmitter dopamine withers, affecting the circuits that control movement. In contrast, the molecules underlying Alzheimer disease- - which affects the entire brain-are only just being unraveled.

Based on the well-mapped circuits in
Parkinson disease, researchers have been able to precisely target their interventions. One technique, deep brain stimulation, emerged from the surgical practice of slicing offending areas such as the subthalamic nucleus. Doctors have now helped thousands of patients by implanting electrodes that shock the same spots, though they remain unsure how it works.

Good animal models, as well as the ability to measure disease progression, have also pushed therapies from lab bench to clinic. In a study published in March (Nat. Med. 9, 589-595; 2003), a UK-based team monitored the symptoms of five people who had glial cell line-derived neurotrophic factor pumped into their brains through their skulls. The protein rejuvenates dopamine-making neurons and has stalled patients' decline by two years, claims team member Clive Svendsen of the University of Wisconsin, Madison.

Other techniques have stirred more controversy. In trials reported in 2001 and August of this year, transplants of nerve tissue from aborted fetuses did little to improve patients' symptoms, and left some with involuntary movements called dyskinesias. But many researchers remain confident that the teething troubles can be ironed out, perhaps by grafting lab-grown stem cells. "I'm a strong believer in cell transplantation," says Patrik Brundin of the Wallenberg Neuroscience Center in Sweden.

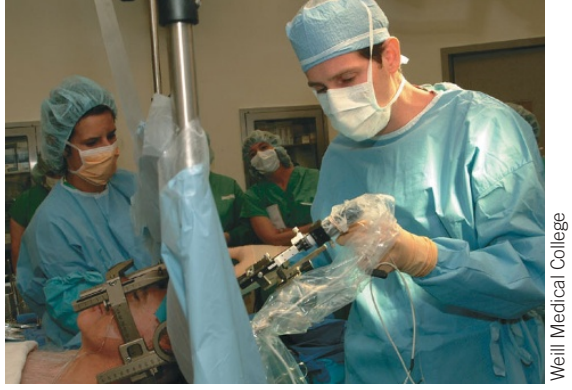

Drill-happy: Experts have criticized the injection of virus particles directly into the brain.

Although most new techniques receive cautious support from the research community, the recent gene therapy trial, which will be extended to 12 patients, has drawn fierce condemnation. Critics worry that the trial proceeded into humans despite insufficient experiments in animals, and that the infused virus might spread to other organs. "I don't think it should have gone ahead," says neurologist Anthony Lang of the University of Toronto.

Whatever their outcome, these techniques might fall by the wayside if researchers can discover what causes dopamine-making cells to die. Says Warren Olanow of Mount Sinai Medical School in New York, "If I had to pick one [approach], it would be understanding the etiology."

Helen Pearson, New York

\section{Animal-rights attacks spark $\mathrm{FBI}$ terror investigation}

A violent attack on Chiron Corp., a California-based biotechnology company, appears to be part of a pattern of increasingly destructive attacks by animal-rights activists in the US, according to the US Federal Bureau of Investigation (FBI).

Two small bombs exploded on 28 August at Chiron's Emeryville campus. The animalrights group Revolutionary Cells-Animal Liberation Brigade claimed responsibility for the attack, citing Chiron's ties to Huntingdon Life Sciences (HLS), a New Jersey-based company that provides animal testing for the pharmaceutical industry. Although no one was injured and damage was limited to a few broken windows, the FBI has opened a domestic terrorism investigation.

Protests against Chiron's relationship with HLS began last May, when activists harassed employees at their homes and vandalized their property. Chiron spokesman John Gallagher says the vandals left "explicit messages about animal rights.” The day before the bombing,

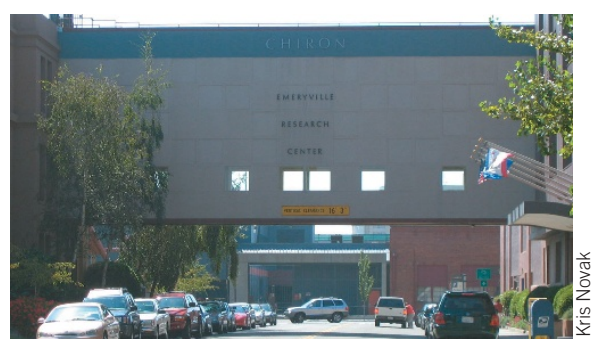

Under seige: Animal-rights activists have targeted California-based Chiron and its 2,000 employees.

Chiron sent an e-mail to its employees warning them about further protests, he adds.

Because the Revolutionary Cells have threatened more attacks on employees' homes, Chiron has increased security for its 2,000 employees at their homes as well as on its campus, which consists of about 20 buildings.

HLS became the focus of attacks by animalrights groups after a British news program in 1998 alleged animal mistreatment at the company's laboratories in England. Animal-rights activists claimed credit for forcing HLS to move its headquarters to New Jersey in 2001, after they pressured European bankers and other financial partners to withdraw support. Gallagher says Chiron does not plan to break off its relationship with HLS, although they have no current contracts.

The attack on Chiron may be part of a new trend, says FBI agent LaRae Quy. "In the past few weeks we've seen a cluster of activity from ecosystems-rights groups in general-from burning Humvees at a dealership in Southern California to the attacks on Chiron," Quy says.

In early August, the Animal Liberation Front took credit for releasing 10,000 minks from a farm in Sultan, Washington. In July, activists protesting the handling of geese during foie gras production vandalized the home and restaurant of a chef that serves the delicacy. But Quy says this may be the first time a biotechnology company in the US has been the target of a bomb attack.

Kris Novak, San Francisco 